Article

\title{
Exogenous $p$-Coumaric Acid Improves Salvia hispanica L. Seedling Shoot Growth
}

\author{
Mbukeni Nkomo ${ }^{1}$, Arun Gokul ${ }^{2}$, Marshall Keyster ${ }^{2,3, *}$ and Ashwil Klein $1, *$ (1) \\ 1 Plant Omics Laboratory, Department of Biotechnology, University of the Western Cape, Bellville 7535, \\ South Africa; 2870274@myuwc.ac.za \\ 2 Environmental Biotechnology Laboratory, Department of Biotechnology, University of the Western Cape, \\ Bellville 7535, South Africa; 3107408@myuwc.ac.za \\ 3 DST-NRF Centre of Excellence in Food Security, University of the Western Cape, Bellville 7530, South Africa \\ * Correspondence: mkeyster@uwc.ac.za (M.K.); aklein@uwc.ac.za (A.K.)
}

Received: 8 October 2019; Accepted: 4 November 2019; Published: 26 November 2019

check for updates

\begin{abstract}
Coumaric acid ( $p$-CA) belongs to a family of natural esters of hydroxycinnamic acid compounds that have been shown to modulate plant growth and metabolism. In this study, we investigated the effect of exogenous $p$-CA on plant growth, reactive oxygen species (ROS)-induced oxidative damage, photosynthetic metabolism, osmolyte content and changes in superoxide dismutase (SOD) enzymatic activity. Exogenous $p$-CA improved Salvia hispanica (chia) growth by significantly enhancing shoot length, fresh and dry weights coupled with augmented levels of total chlorophyll and carotenoid contents. Furthermore, $p$-CA also triggered an induction in proline, glycine betaine (GB) and superoxide $\left(\mathrm{O}_{2}{ }^{-}\right)$levels while no changes were observed for hydrogen peroxide $\left(\mathrm{H}_{2} \mathrm{O}_{2}\right)$ and downstream malondialdehyde (MDA) content. Also, no change in SOD activity was observed in the $p$-CA treatment relative to the control. Therefore, the results suggest that exogenous $p$-CA improves chia seedling growth possibly via activation of a ROS-signalling pathway involving $\mathrm{O}_{2}{ }^{\cdot-}$ under the control of proline accumulation.
\end{abstract}

Keywords: chia; chlorophyll content; $p$-coumaric acid; osmoprotectants; oxidative stress; proline; superoxide dismutase

\section{Introduction}

Phenolic acids are divided into two groups based on their chemical structure, namely hydroxybenzoic and hydroxycinnamic [1]. Hydroxycinnamic acids (includes p-coumaric-, caffeic-, ferulic-, and sinapic acid) derived from the phenylalanine pathway, have gained recent attention due to their revealed properties, such as antimicrobial, antitumor, anti-inflammatory, antioxidant and other health benefits like antidiabetic activity [2-4]. In plants, these hydroxycinnamic acids have been referred to as allelochemicals and are commonly found in soils at concentrations ranging from 0.01 to $0.1 \mathrm{mM}$ and have been shown to affect plant growth at concentrations of up to $10 \mathrm{mM}[5,6]$. Of these hydroxycinnamic acids, $p$-CA resides at a metabolically important position, linked to the synthesis of other hydroxycinnamic acids such as caffeic-, ferulic- and sinapic acid. A few lines of research have shown that $p$-CA reduced the rate of seed germination, root length and biomass in different plant species [7-11]. This led to a general perception that exogenously applied $p$-CA restricts plant growth and development in various plant species [7-13]. Jones et al. [14] showed that exogenous application of caffeic acid (a derivative of $p$-CA) improved the growth of chia plants through differential regulation of photosynthetic metabolism, ROS content and antioxidant enzyme activities under salt stress conditions. This result is in contradiction to what was reported for legume plants $[15,16]$. Antioxidant enzymes such as SOD, ascorbate peroxidase (APX) and catalase (CAT) differentially regulate ROS biosynthesis. 
These ROS molecules include $\mathrm{O}_{2}{ }^{--}, \mathrm{H}_{2} \mathrm{O}_{2}$ and hydroxyl radicals $\left(\mathrm{OH}^{*}\right)$ and if not controlled can lead to oxidative stress manifested as enhanced cellular death. However, increased ROS molecules (in moderation)-for example $\mathrm{O}_{2}{ }^{--}$and $\mathrm{H}_{2} \mathrm{O}_{2}$ - have been shown to act as signalling molecules in various plant species [17,18]. Furthermore, a study by Gokul et al. [19] showed that $\mathrm{O}_{2}{ }^{--}$and $\mathrm{H}_{2} \mathrm{O}_{2}$ regulate physio-biochemical responses in Brassica napus plants via the modulation of SOD and APX activity, which in turn led to increased seedling growth. This evidence suggests that the mechanism controlling redox homeostasis of ROS molecules can be exploited to improve plant growth. To our knowledge, no study has investigated the effect of exogenous application of $p$-CA on the physio-biochemical responses (including ROS homeostasis) of pseudocereal plants.

Chia is an oilseed pseudocereal plant known for its nutritional and health promoting properties. The seed is a natural source of omega- 3 fatty acids ( $\alpha$-linolenic acid), soluble and insoluble fibers, and proteins in addition to other important nutritional components, such as vitamins, minerals, and natural antioxidants [20,21]. Furthermore, it has been shown that chia plants (seeds and leaves) contain various bioactive components such as tocopherols and phenolic compounds, which reduces the risk of liver, cardiovascular and obesity-related diseases [22-26]. In view of the nutritional and health-promoting properties of chia plants in recent years, there has been considerable interest to explore the biological and technological potential of this plant. In this study, we investigated the effect of exogenously applied $p$-CA on the growth, photosynthetic pigments, osmolyte content, ROS-induce oxidative damage and changes in SOD activity in chia seedlings.

\section{Results}

\section{1. $p$-CA Improves Chia Seedling Growth}

In this study we investigated the effect of exogenous application of $p$-CA on plant growth and chlorophyll content. The results show that exogenous $p$-CA significantly increase shoot growth of chia seedlings (Figure 1), as observed for shoot height (SH), fresh weight (FW) and dry weight (DW). Exogenous p-CA improved SH by $37.2 \%$ when compared to control plants (Figure 1B). A similar trend was observed for FW and DW. On average, FW and DW were enhanced by $43.6 \%$ and $54.1 \%$, respectively, under $p$-CA treatment relative to the control (Figure 1C,D). 

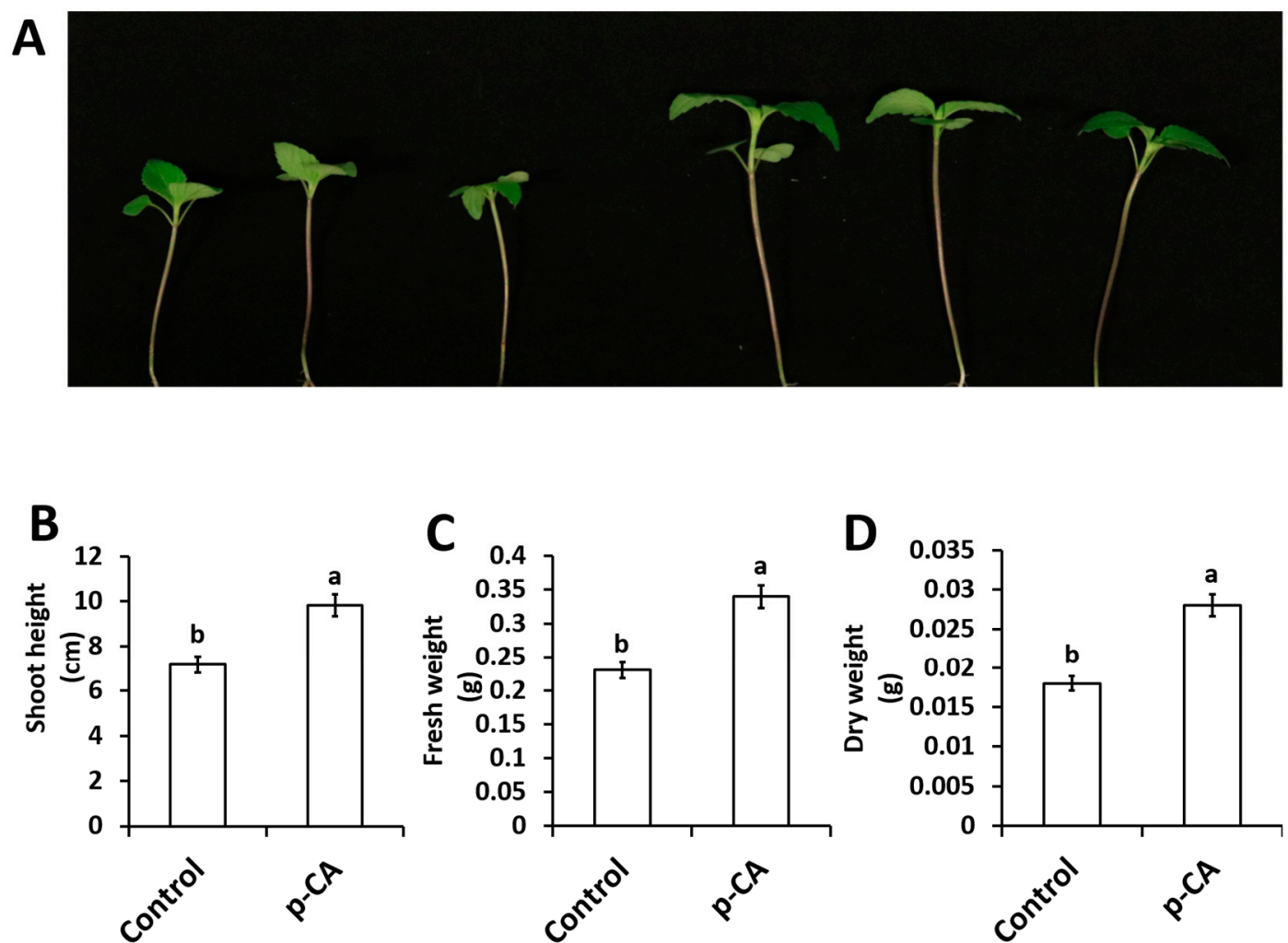

Figure 1. Representative chia seedling shoots under control and $p$-CA treatments (A). Shoot height (B), shoot fresh weight $(\mathbf{C})$ and shoot dry weight $(\mathbf{D})$ of chia seedlings treated with $p$-CA. Data represent the mean $( \pm$ SE) from six independent experiments. Different letters represent statistical significance at $p<0.05$ (Tukey-Kramer test).

\subsection{The Effect of Exogenous $p$-CA on Chlorophyll Metabolism and Osmolyte Content}

Both chlorophyll $a$ and chlorophyll $b$ content showed similar results that significantly increased by $36.2 \%$ and $38.5 \%$, respectively, when compared to the control. Parallel to chlorophyll $a$ and chlorophyll $b$, there was a significant increase in total chlorophyll (37.6\%) and carotenoid (25.1\%) content in response to exogenous application of $p$-CA (Table 1). The $p$-CA treatment also caused a significant increase in osmolyte compounds (GB and proline), when compared to the control. Furthermore, there was a significant increase in both proline $(170 \%)$ and GB $(22.4 \%)$ content (Table 1$)$ when compared to the control.

Table 1. Chlorophyll and osmolyte concentration in chia seedling shoots in response to $p$-Coumaric acid. Data represent the means $( \pm \mathrm{SE})$ of six independent experiments and different letters per row indicate the mean values that are significant different at $p<0.05$ using the Tukey-Kramer test.

\begin{tabular}{ccc}
\hline Trait $\left(\mu\right.$ g.g $\left.^{-1} \mathbf{F W}\right)$ & Control & $p$-CA \\
\hline Chlorophyll $a$ & $15.70 \pm 0.83^{\mathrm{b}}$ & $21.30 \pm 0.88^{\mathrm{a}}$ \\
Chlorophyll $b$ & $24.80 \pm 1.01^{\mathrm{b}}$ & $34.40 \pm 0.50^{\mathrm{a}}$ \\
Total Chlorophyll & $40.50 \pm 1.80^{\mathrm{b}}$ & $55.70 \pm 1.38^{\mathrm{a}}$ \\
Carotenoids & $1009.70 \pm 10.17^{\mathrm{b}}$ & $1263.30 \pm 8.82^{\mathrm{a}}$ \\
Glycine Betaine & $6030 \pm 233.03^{\mathrm{b}}$ & $7380 \pm 60.02^{\mathrm{a}}$ \\
Proline & $1.21 \pm 0.02^{\mathrm{b}}$ & $3.26 \pm 0.04^{\mathrm{a}}$ \\
\hline
\end{tabular}




\subsection{Effects of p-CA on Superoxide Radical and Superoxide Dismutase Activity}

Exogenous application of $p$-CA significantly increased $\mathrm{O}_{2}{ }^{--}$content by $522 \%$ relative to the control (Figure 2A).
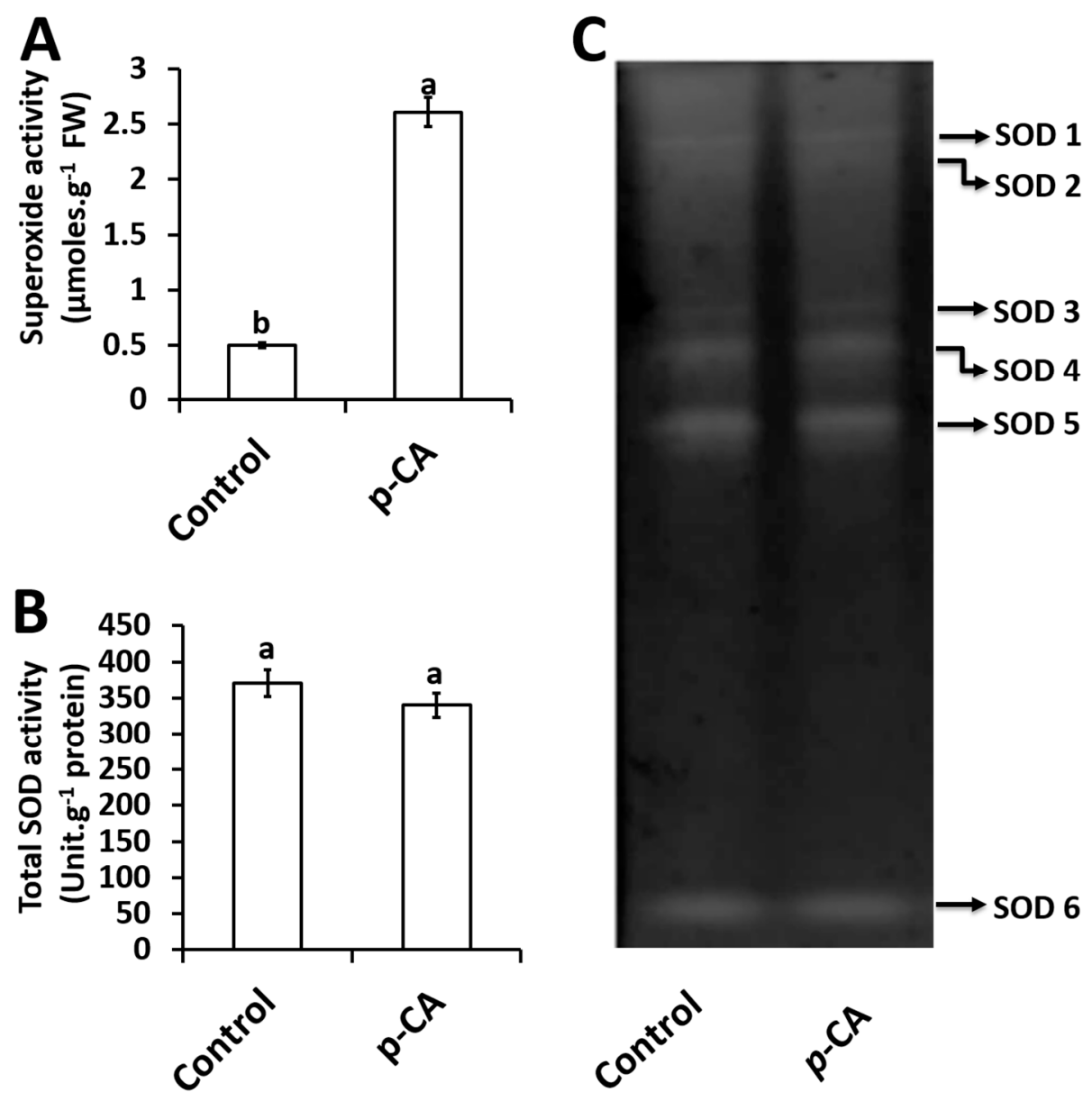

Figure 2. Superoxide content (A), total SOD activity (B) and the activity of individual SOD isoforms (C) in control and $p$-CA treated chia seedlings. Data represent the mean $( \pm \mathrm{SE})$ from six independent experiments. Different letters represent statistical significance at $p<0.05$ (Tukey-Kramer test).

For total SOD activity, no significant changes were observed in response to exogenous $p$-CA when compared to the control (Figure 2B). A total of six SOD isoforms were detected and named SOD1-6 (Figure 2C). Upon visual inspection together with densitometry analysis (data not shown) no significant difference was observed for all 6 isoforms in the $p$-CA treatment when compared to the control (Figure 2C).

\subsection{Effects of Exogenous Application of p-CA on $\mathrm{H}_{2} \mathrm{O}_{2}$ Content and the Extent of Lipid Peroxidation}

The effect of exogenous $p$-CA on $\mathrm{H}_{2} \mathrm{O}_{2}$ content and MDA content (an indicator of lipid peroxidation) in the shoots of chia seedlings were investigated. Compared to the control, $p$-CA had no effect on $\mathrm{H}_{2} \mathrm{O}_{2}$ content (Figure 3A). Based on the results presented here, no significant changes in the extent of lipid peroxidation was observed in shoots of chia seedlings treated with $p$-CA (Figure 3B). 

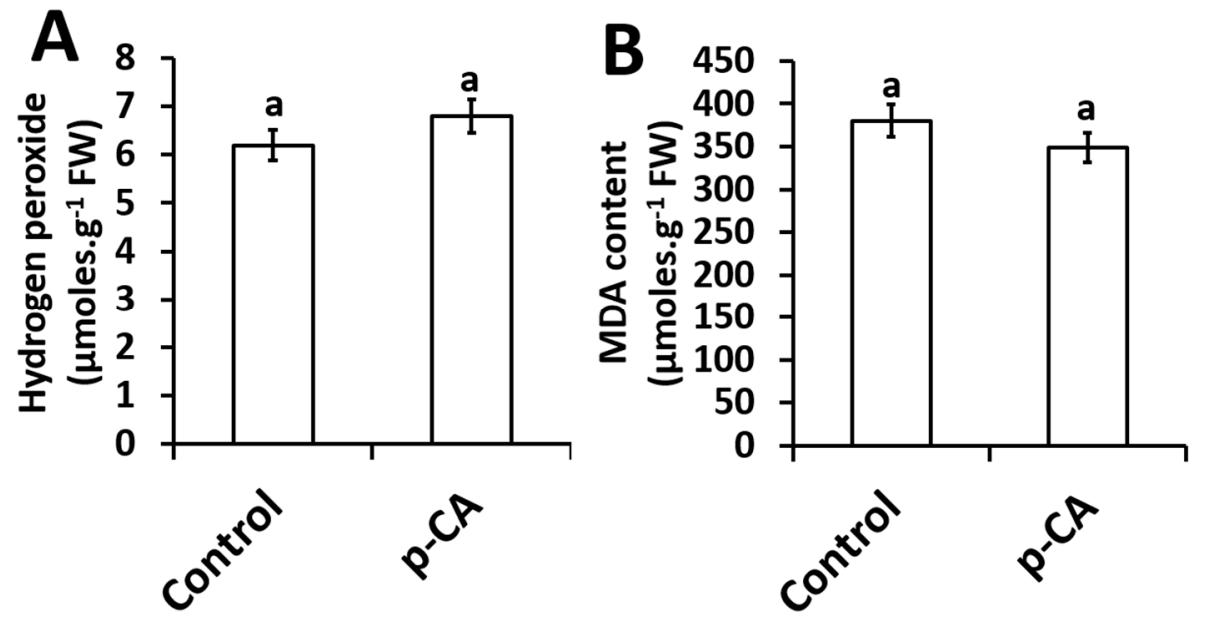

Figure 3. Hydrogen peroxide content (A) and MDA content $(\mathbf{B})$ in chia seedling shoots under control and $p$-CA treatment. Data represent the mean $( \pm \mathrm{SE})$ six independent experiments. Different letters represent statistical significance at $p<0.05$ (Tukey-Kramer test).

\section{Discussion}

In this study, we have dissected the role of exogenous $p$-CA on chia plant growth and biochemistry. Exogenous application of $p$-CA has been studied previously in various plant species $[7,9,13,27]$. Reigosa and colleagues [11] performed a germination study on six weed species using different phenolic compounds including $p$-CA and observed that higher concentrations of $p$-CA inhibited the rate of germination while low concentrations had no significant effect on all six weed species. That result is in agreement with our preliminary investigation conducted on chia seeds on the rate of germination under different concentrations of $p$-CA $(0 \mu \mathrm{M}, 100 \mu \mathrm{M}, 250 \mu \mathrm{M}, 500 \mu \mathrm{M}$, and $1000 \mu \mathrm{M})$. We observed that the final seed germination percentage was similar across all treatments except for $1000 \mu \mathrm{M}$ at which no germination occurred (see Supplementary Data; Figure S1B). Our data also showed no effect on sprout growth across all treatments with the exception at $500 \mu \mathrm{M} p$-CA (see Supplementary Data; Figure S1A). Furthermore, we identified $100 \mu \mathrm{M}$ as a suitable concentration for further studies on chia seedling growth, physiology and biochemistry. Previous work on $p$-CA supplementation demonstrated that treatment with $100 \mu \mathrm{M} p$-CA reduced cucumber leaves [28]. Similar results were also observed in other studies using various concentrations $(100 \mu \mathrm{M}-1000 \mu \mathrm{M})$ of $p$-CA. In those studies, it was demonstrated that exogenous application of $p$-CA had inhibitory effects on root length, root fresh and dry weights of many tested plant species [7-10,13,27]. Contrastingly, an opposite phenomenon was observed in our study because we observed that treatment with $100 \mu \mathrm{M}$ $p$-CA promoted chia seedling growth and biomass (Figure 1). In addition, we examined chlorophylls $a$ and $b$, total chlorophyll and carotenoid contents in the shoots of chia seedlings treated with $p$-CA compared to untreated controls. We observed an increase in chlorophyll pigments (Table 1) in chia seedlings treated with $p$-CA, which suggests that exogenous $p$-CA positively regulates chlorophyll synthesis in chia plants. Therefore, we hypothesized that the increase in growth could be as a result of an increase in chlorophyll pigments. This hypothesis is supported by Yan et al. [29] that observed a positive correlation between chlorophyll content and biomass. Contrasting results were observed by [30], which treated soybean (Glycine max) seedlings with exogenous $p$-CA and observed a reduction in chlorophyll content. Einhellig and colleagues [30] suggested that the decrease in chlorophyll content in soybean might be as a result of other secondary responses, as the same phenomenon was not observed in sorghum seedlings. These secondary responses include ROS molecules such as $\mathrm{O}_{2}{ }^{\cdot-}$, which have been shown to interact directly with chlorophyll $a$ ultimately leading to chlorophyll degradation [31], however Yan et al. [29] observed an increase in chlorophyll content and $\mathrm{O}_{2}{ }^{-{ }^{-}}$content in response to exogenous salicylic acid and sodium nitroprusside (nitric oxide donor) in wheat. In 
contrast, exogenous caffeic acid decreased $\mathrm{O}_{2}{ }^{--}$content in soybean plants [32], which led to unaltered levels of chlorophyll content [16]. These studies point to a complex interaction between $\mathrm{O}_{2}{ }^{--}$and chlorophyll in different plants, which has not been elucidated to date. In our study, higher levels of $\mathrm{O}_{2}{ }^{\cdot-}$ were detected under exogenous $p$-CA and the scavenging mechanism of $\mathrm{O}_{2}{ }^{\cdot-}$ did not involve a direct role of SOD enzymes. We observed that total SOD activity and individual SOD isoforms were unaltered in $p$-CA treated chia seedlings, which suggests that other mechanisms of $\mathrm{O}_{2}{ }^{--}$scavenging were possibly triggered by exogenous $p$-CA in the chia seedlings. This phenomenon was also observed by Yan et al. [29], where the increase in $\mathrm{O}_{2}{ }^{--}$did not result in an increase in SOD activity in response to exogenous sodium nitroprusside. Contrastingly, Klein et al. [32] showed that exogenous caffeic acid decreased $\mathrm{O}_{2}{ }^{--}$content in soybean plants whereas a significant increase in SOD activity was observed. These studies show a complex interaction between $\mathrm{O}_{2} \cdot{ }^{\cdot-}$ accumulation and scavenging via SOD, which is not well understood.

We also observed that $\mathrm{H}_{2} \mathrm{O}_{2}$ levels were similar to those of the control seedlings. This finding supports our result where no changes in SOD activity were observed. According to the Asada-Halliwell pathway, SOD scavenges $\mathrm{O}_{2}{ }^{--}$and produces downstream $\mathrm{H}_{2} \mathrm{O}_{2}$, which has the ability to oxidize polyunsaturated fatty acids (PUFA) ultimately producing secondary products such as MDA, which is an indicator of lipid peroxidation [33]. Lipid peroxidation is a marker for testing membrane cellular damage following oxidative stress [34]. In our study, we observed unaltered levels of MDA in $p$-CA treated seedlings when compared to the controls (Figure $3 \mathrm{~B}$ ), which might be expected considering no changes in $\mathrm{H}_{2} \mathrm{O}_{2}$ content were observed under $p$-CA supplementation.

The protective effects of compatible osmolytes (GB and proline) in limiting membrane injury have been reported and studies have shown that proline can scavenge ROS molecules $[35,36]$. Furthermore, compatible osmolytes can also act as osmoprotectants of cellular molecules under a wide range of abiotic stresses [37-40]. Matysik and colleagues [41] showed that proline can protect the photosystem PSII by scavenging $\mathrm{O}_{2}^{--}$thus reducing lipid peroxidation in the thylakoid membranes. However, our study is in agreement with the results obtained by [14], which showed that exogenous supplementation of hydroxycinnamic acids (caffeic acid) increased chia plant growth. We propose a mechanism by which exogenous application of $p$-CA improves the growth of chia shoots, possibly through the activation of $\mathrm{O}_{2}{ }^{--}$. This is indicated by our experiments where both $\mathrm{H}_{2} \mathrm{O}_{2}$ and total SOD activity were not affected (Figure 3). In support of our results, there are several reports showing that, besides directly scavenging $\mathrm{O}_{2}^{\cdot-}$ [42], $p$-CA can also increase proline accumulation, which has also been linked to $\mathrm{O}_{2}{ }^{--}$ scavenging $[26,35]$.

\section{Materials and Methods}

\subsection{Plant Material and Growth Conditions}

Chia seeds purchased from Faithful to Nature, Cape Town, South Africa were used in this experiment. The seeds were germinated on wet filter paper in the dark for a period of $72 \mathrm{~h}$. Germinated seeds were transferred to $19 / 20 \mathrm{~cm}$ plastic pots containing moist promix growth medium (Stodels Garden Centre, Brackenfell, South Africa) and allowed to grow on a $27 / 19^{\circ} \mathrm{C}$ day/night temperature cycle under a $16 / 8 \mathrm{~h}$ dark cycle at a photosynthetic photon flux density of $300 \mu \mathrm{mol}$ photons $\cdot \mathrm{m}^{-2} \cdot \mathrm{s}^{-1}$ during the day phase until the end of the experiment. Seedlings were grown in a completely randomized design to eliminate the effect of variations in environmental conditions at different positions in the growth room.

Plants at the same developmental stage and of similar height were selected for all experiments. Control plants were supplemented with $50 \mathrm{~mL}$ of Nitrosol $^{(\mathrm{R})}$ solution diluted in water (1:300). For treatment with $p$-CA, plants were supplemented with Nitrosol $^{(\mathrm{R})}$ containing $100 \mu \mathrm{M} p$-CA (at 2-day intervals) for a period of 14 days. 


\subsection{Measurement of Plant Growth}

Chia seedlings were carefully removed from the growth medium to avoid damage. Subsequently, the roots were separated from the shoots to prevent erroneous data interpretation caused by possible root damage. The shoots from each treatment were scored for length (SL), fresh weight (FW) and dry weight (DW). The DW was determined by drying the seedlings in an oven at $55^{\circ} \mathrm{C}$ for $48 \mathrm{~h}$ as described by [19].

\subsection{Chlorophyll Estimation}

Total chlorophyll content in the shoots of chia seedlings was estimated using a method previously described by [43]. Freshly harvested shoots (200 mg per treatment) was homogenized with $5 \mathrm{~mL}$ of dimethylsulfoxide (DMSO) and incubated at $65^{\circ} \mathrm{C}$ for $3 \mathrm{~h}$. The absorbance rates of the extract $(200 \mu \mathrm{L})$ were recorded at $645 \mathrm{~nm}$ and $663 \mathrm{~nm}$, with DMSO used as a blank using a FLUOstar Omega UV-visible spectrophotometer (BMG LabTech GmbH, Ortenberg, Germany).

\subsection{Protein Extraction for Biochemical Analysis}

Shoots from all treatments were harvested and ground into a fine powder using liquid nitrogen. Shoots $(0.1 \mathrm{~g})$ was homogenized in $1 \mathrm{~mL}$ of PVP buffer $\left(40 \mathrm{mM} \mathrm{K}_{2} \mathrm{HPO}_{4}\right.$ at $\mathrm{pH} 7.4 ; 1 \mathrm{mM}$ EDTA; $5 \%$ PVP MW = 40 000; 5\% glycerol in distilled $\mathrm{H}_{2} \mathrm{O}$ ) for the measurement and detection of SOD enzymatic activity. Protein concentrations were determined using the RC DC Protein Assay Kit 11 (Bio-Rad Laboratories).

\subsection{Assays for ROS Content}

Superoxide $\left(\mathrm{O}_{2}{ }^{-}\right)$content in the shoots of chia seedlings was quantified using a method previously described in [19]. Superoxide concentrations were determined by submerging intact seedling shoots in a solution containing; $10 \mathrm{mM} \mathrm{KCN}$ (to inhibit $\mathrm{Cu} / \mathrm{Zn} \mathrm{SODs}$ ), $10 \mathrm{mM} \mathrm{H}_{2} \mathrm{O}_{2}$ (to inhibit $\mathrm{Mn}$ and Cu/Zn SODs), 2\% (w/v) SDS (to inhibit Mn and Fe SODs), $80 \mathrm{mM}$ Nitroblue tetrazolium chloride (NBT) and $50 \mathrm{mM}$ potassium phosphate ( $\mathrm{pH} 7.0$ ) and incubated for $20 \mathrm{~min}$. After incubation, shoots were homogenized and centrifuged at $10000 \times \mathrm{g}$ for $5 \mathrm{~min}$. The resulting supernatant was spectrophotometrically analysed at $600 \mathrm{~nm}$ using a FLUOstar Omega UV-visible spectrophotometer (BMG LabTech GmbH, Ortenberg, Germany). The superoxide concentration was calculated using the NBT extinction coefficient of $12.8 \mathrm{mM} \cdot \mathrm{cm}^{-1}$. Hydrogen peroxide $\left(\mathrm{H}_{2} \mathrm{O}_{2}\right)$ content was measured in shoots of chia seedlings, using a method previously described by [44]. Briefly, shoot material (0.1 g) were ground to a fine powder in liquid nitrogen and homogenized in $1 \mathrm{~mL}$ of cold $6 \%(w / v)$ TCA. The extracts were centrifuged at 12000 $\times \mathrm{g}$ for $30 \mathrm{~min}$ at $4{ }^{\circ} \mathrm{C}$ and $50 \mu \mathrm{L}$ of the supernatant was used to initiate the reaction in a mixture (total volume of $200 \mu \mathrm{L}$ ) containing $5 \mathrm{mM} \mathrm{K}_{2} \mathrm{HPO}_{4}(\mathrm{pH} 5.0)$ and $0.5 \mathrm{M}$ potassium iodide (KI). The reaction mixture was incubated at $25^{\circ} \mathrm{C}$ for $20 \mathrm{~min}$ and the absorbance readings were recorded at $390 \mathrm{~nm}$ using a FLUOstar Omega UV-visible spectrophotometer (BMG LabTech GmbH, Ortenberg, Germany). $\mathrm{H}_{2} \mathrm{O}_{2}$ content was calculated using a standard curve based on the absorbance of $\mathrm{H}_{2} \mathrm{O}_{2}$ standards.

\subsection{Determination of MDA Content}

The extent of lipid peroxidation (MDA) in the shoots of chia seedlings were quantified as described by [45]. Briefly, shoot material $(0.1 \mathrm{~g})$ were ground to a fine powder in liquid nitrogen and homogenized in $1 \mathrm{~mL}$ of cold $6 \%(w / v)$ TCA. Aliquots of the supernatant $(100 \mu \mathrm{L})$, were mixed with $400 \mu \mathrm{L}$ of $0.5 \%$ thiobarbituric acid (TBA; prepared in $20 \%$ TCA). The mixture was incubated at $95{ }^{\circ} \mathrm{C}$ for 30 min and the reaction was terminated on ice for $5 \mathrm{~min}$. The mixture was centrifuged at $12000 \times \mathrm{g}$ for $5 \mathrm{~min}$ at $4{ }^{\circ} \mathrm{C}$. The absorbance of the supernatant was recorded at $532 \mathrm{~nm}$ and $600 \mathrm{~nm}$ using a FLUOstar Omega UV-visible spectrophotometer (BMG LabTech GmbH, Ortenberg, Germany). After subtracting the non-specific absorbance, the MDA concentration was calculated using the extinction coefficient of $155 \mathrm{mM} \cdot \mathrm{cm}^{-1}$. 


\subsection{Quantification of SOD Activity}

Total SOD activity was measured using a method previously described by [46]. The protein extract $(10 \mu \mathrm{L})$ was mixed with $190 \mu \mathrm{L}$ of the assay buffer $\left(50 \mathrm{mM} \mathrm{K}_{2} \mathrm{HPO}_{4}, \mathrm{pH} 7.8,0.1 \mathrm{mM}\right.$ EDTA, $10 \mathrm{mM}$ methionine, $5 \mu \mathrm{M}$ riboflavin, $0.1 \mathrm{mM} \mathrm{NBT}$ ) and incubated at room temperature for 20 min under fluorescent light. Subsequently, the absorbance readings were recorded at $560 \mathrm{~nm}$ using a FLUOstar Omega UV-visible spectrophotometer (BMG LabTech GmbH, Ortenberg, Germany). SOD activity was calculated based on the amount of enzyme that was required to cause a $50 \%$ reduction of NBT.

In-gel activity of individual SOD isoforms was detected in the shoots of chia seedlings according to a method described by [32]. Protein extracts $(100 \mu \mathrm{g})$ from each treatment were separated on a $10 \%$ $(\mathrm{v} / \mathrm{v})$ resolving native polyacrylamide gel at $4{ }^{\circ} \mathrm{C}$. SOD activity of individual isoforms was detected by photochemical staining with riboflavin and NBT.

\subsection{Determination of Proline Content}

Total free proline content in the shoots of chia plants was estimated using [47] and modified by [48]. Briefly, fresh shoot material from each treatment $(0.1 \mathrm{~g})$ were homogenized in $500 \mu \mathrm{L}$ of $3 \%$ $(w / v)$ sulphosalicylic acid using a mortar and pestle. About $200 \mu \mathrm{L} \mathrm{ml}$ of each homogenate was mixed with $200 \mu \mathrm{L}$ of glacial acetic acid to which $200 \mu \mathrm{L}$ of ninhydrin was added. The reaction mixture was boiled in a water bath at $100^{\circ} \mathrm{C}$ for $30 \mathrm{~min}$ and immediately cooled in an ice bath. After cooling, $400 \mu \mathrm{L}$ of toluene was added to the reaction mixture. After thorough mixing, the chromophore containing toluene was separated and the absorbance of the red color developed was read at $520 \mathrm{~nm}$ against the toluene blank on FLUOstar Omega UV-visible spectrophotometer (BMG LabTech GmbH, Ortenberg, Germany).

\subsection{Determination of Glycine Betaine}

Glycine betaine (GB) content in the shoots of chia seedlings was estimated using a method previously described in [49] with slight modifications from that described in [50]. Shoot material $(0.25 \mathrm{~g})$ from each treatment were ground to a fine powder in liquid nitrogen. The tissue was incubated in tubes containing $20 \mathrm{~mL}$ of deionized water for $24 \mathrm{~h}$ at $25^{\circ} \mathrm{C}$. The samples were filtered and mixed with $2 \mathrm{~N} \mathrm{H}_{2} \mathrm{SO}_{4}$. An aliquot $(250 \mu \mathrm{L})$ was transferred into a test tube and cooled in ice water for $1 \mathrm{~h}$. Cold potassium iodide-iodine reagent $(100 \mu \mathrm{L})$ was added, vortexed, and then centrifuged at $1000 \times \mathrm{g}$ for $30 \mathrm{~min}$ at $4{ }^{\circ} \mathrm{C}$. The sample was incubated for $24 \mathrm{~h}$ at $4{ }^{\circ} \mathrm{C}$. The formed periodite crystals were dissolved in $14 \mathrm{~mL}$ of 1,2-dichloroethane with gentle agitation at room temperature for $48 \mathrm{~h}$. The absorbance was recorded at $365 \mathrm{~nm}$ using a FLUOstar Omega UV-visible spectrophotometer (BMG LabTech GmbH, Ortenberg, Germany).

\subsection{Statistical Analysis}

All experiments described were performed six times independently. For superoxide content, shoot height, shoot fresh weight, shoot dry weight measurements, 30 individual chia seedlings per treatment were analyzed. For all other experiments, 50 chia seedling shoots were homogenized per treatment. For statistical analysis, the one-way analysis of variance (ANOVA) test was used for all data, and means (for six independent experiments) were compared according to the Tukey-Kramer test at $5 \%$ level of significance, using GraphPad Prism 5.03 software.

\section{Conclusions}

After summarizing studies on exogenous $p$-CA on plants in a hypothetical model (Figure S2) and incorporating our findings of this study, we conclude that $\mathrm{O}_{2}{ }^{--}$plays a crucial role in the downstream signalling mechanism of $p$-CA in chia seedlings. This hypothesis was also observed by [19] where increases in $\mathrm{O}_{2}{ }^{--}$led to improved growth of Brassica napus seedlings. However, in contrast to [19], our results showed that the regulation of $\mathrm{O}_{2}{ }^{\cdot-}$ content in chia seedlings does not occur via SOD but 
rather through direct scavenging of $\mathrm{O}_{2}{ }^{--}$by $p$-CA $[51,52]$. Furthermore, we hypothesize that the redox buffering capacity of proline [38] (after direct increase by $p$-CA) specifically with regards to $\mathrm{O}_{2}{ }^{--}$plays a major role in synthesis and scavenging of the $\mathrm{O}_{2}{ }^{--}$in addition to the direct scavenging capacity of the $p$-CA. This carefully controls the $\mathrm{O}_{2}{ }^{--}$levels without triggering an increase in SOD activity. Furthermore, we observed no changes in $\mathrm{H}_{2} \mathrm{O}_{2}$ content and we attribute this to the unchanged SOD activity. We also conclude that the increase in GB by exogenous $p$-CA application led to improved chlorophyll and photosynthetic pigments. This result is supported by findings from [53] which highlighted the role of GB in improving photosynthetic pigments. We hypothesize that $p$-CA improves chia seedling growth via GB and proline activation. Future work should investigate whether the GB pathway occur separately or independently from the proline pathway in chia seedlings treated with -CA.

Supplementary Materials: The following are available online at http://www.mdpi.com/2223-7747/8/12/546/s1, Figure S1. Concentration-dependant germination of chia seedlings (A-B), Method S1: Evaluation of seed germination Figure S2: Schematic model of $p$-CA signalling in chia seedlings.

Author Contributions: Conceptualization, A.K.; methodology, M.N. and A.G.; validation, M.N. and A.G.; formal analysis, M.N., A.G., M.K. and A.K.; investigation, M.N. and A.G.; resources, M.N., M.K. and A.K.; data curation, M.N., M.K. and A.K.; writing—original draft preparation, M.N.; writing—review and editing, A.G., M.K. and A.K.; supervision, M.K. and A.K.; project administration, A.K.; funding acquisition, A.K. and M.K.

Funding: This work was supported by the National Research Foundation of South Africa awarded to A.K. and M.K. (Grant Numbers: 107023, 115280, 116,346 and 109083); and the University of the Western Cape. M.K. was also supported by the DST-NRF Centre of Excellence in Food Security (Project ID 170202).

Conflicts of Interest: The authors declare no conflict of interest.

\section{Abbreviations}

$\begin{array}{ll}p \text {-CA } & p \text {-coumaric acid } \\ \text { DW } & \text { dry weights } \\ \text { FW } & \text { fresh weights } \\ \text { GB } & \text { glycine betaine } \\ \text { KI } & \text { potassium iodide } \\ \text { MDA } & \text { malondialdehyde } \\ \text { PUFA } & \text { polyunsaturated fatty acids } \\ \text { PVP } & \text { polyvinylpyrrolidone } \\ \text { ROS } & \text { reactive oxygen species } \\ \text { SH } & \text { shoot height } \\ \text { SOD } & \text { superoxide dismutase } \\ \text { TBA } & \text { thiobarbituric acid } \\ \text { TCA } & \text { trichloroacetic acid }\end{array}$

\section{References}

1. Shahidi, F.; Yeo, J. Bioactivities of phenolics by focusing on suppression of chronic diseases: A review. Int. J. Mol. Sci. 2018, 19, 1573. [CrossRef] [PubMed]

2. Heleno, S.A.; Martins, A.; Queiroz, M.J.R.; Ferreira, I.C. Bioactivity of phenolic acids: Metabolites versus parent compounds: A review. Food Chem. 2015, 173, 501-513. [CrossRef] [PubMed]

3. Kwak, J.Y.; Park, S.; Seok, J.K.; Liu, K.H.; Boo, Y.C. Ascorbyl coumarates as multifunctional cosmeceutical agents that inhibit melanogenesis and enhance collagen synthesis. Arch. Dermatol. Res. 2015, 307, $635-643$. [CrossRef] [PubMed]

4. Yang, W.S.; Jeong, D.; Yi, Y.; Park, J.G.; Seo, H.; Moh, S.H.; Hong, S.; Cho, J.Y. IRAK1/4-targeted anti-inflammatory action of caffeic acid. Mediat. Inflamm. 2013, 2013, 518183. [CrossRef]

5. Bubna, G.A.; Lima, R.B.; Zanardo, D.Y.L.; Dos Santos, W.D.; Ferrarese, M.L.L.; Ferrarese-Filho, O. Exogenous caffeic acid inhibits the growth and enhances the lignification of the roots of soybean (Glycine max). J. Plant Physiol. 2011, 168, 1627-1633. [CrossRef] 
6. Macias, F. Allelopathy in the search for natural herbicides model. In Allelopathy, Current Status and Future Goals; Dakshini, K.M.M., Einhellig, F.A., Eds.; ACS Publications: Washington, DC, USA, 1995; pp. 310-329.

7. Baleroni, C.R.S.; Ferrarese, M.L.; Braccini, A.L.; Scapim, C.A.; Ferrarese-Filho, O. Effects of ferulic and p-coumaric acids on canola (Brassica napus L. cv. Hyola 401) seed germination. Seed Sci. Technol. 2000, 28, 201-207.

8. Janovicek, K.J.; Vyn, T.J.; Voroney, R.P.; Allen, O.B. Early corn seedling growth response to phenolic acids. Can. J. Plant Sci. 1997, 77, 391-393. [CrossRef]

9. Patterson, D.T. Effects of allelopathic chemicals on growth and physiological responses of soybean (Glycine max L.). Weed Sci. 1981, 29, 53-59. [CrossRef]

10. Politycka, B.; Mielcarz, B. Involvement of ethylene in growth inhibition of cucumber roots by ferulic and p-coumaric acids. Allelopath. J. 2007, 19, 451-460.

11. Reigosa, M.J.; Souto, X.C.; Gonzálezm, L. Effect of phenolic compounds on the germination of six weeds species. Plant Growth Regul. 1999, 28, 83-88. [CrossRef]

12. Orcaray, L.; Igal, M.; Zabalza, A.; Royuela, M. Role of exogenously supplied ferulic and $p$-coumaric acids in mimicking the mode of action of acetolactate synthase inhibiting herbicides. J. Agric. Food Chem. 2011, 59, 10162-10168. [CrossRef] [PubMed]

13. Zanardo, D.I.L.; Lima, R.B.; Ferrarese, M.L.L.; Bubna, G.A.; Ferrarese-Filho, O. Soybean root growth inhibition and lignification induced by $p$-coumaric acid. Environ. Exp. Bot. 2009, 66, 25-30. [CrossRef]

14. Jones, S.; Keyster, M.; Klein, A. Exogenous caffeic acid alters physiological and molecular responses in chia (Salvia hispanica L.). S. Afr. J. Bot. 2017, 100, 339-340. [CrossRef]

15. Batish, D.R.; Singh, H.P.; Kaur, S.; Kohli, R.K.; Yadav, S.S. Caffeic acid affects early growth, and morphogenetic response of hypocotyl cuttings of mung bean (Phaseolus aureus). J. Plant Physiol. 2008, 165, 297-305. [CrossRef]

16. Klein, A.; Keyster, M.; Ludidi, N. Response of soybean nodules to exogenously applied caffeic acid during $\mathrm{NaCl}$-induced salinity. S. Afr. J. Bot. 2015, 96, 13-18. [CrossRef]

17. Kranner, I.; Roach, T.; Beckett, R.C.; Whitaker, C. Extracellular production of reactive oxygen species during seed germination and early seedling growth in Pisum sativum. Plant Physiol. 2010, 167, 805-811. [CrossRef]

18. El-Maarouf-Bouteau, H.; Bailly, C. Oxidative signaling in seed germination and dormancy. Plant Signal. Behav. 2008, 3, 175-182. [CrossRef]

19. Gokul, A.; Roode, E.; Klein, A.; Keyster, M. Exogenous 3, 3'-diindolylmethane increases Brassica napus L. seedling shoot growth through modulation of superoxide and hydrogen peroxide content. J. Plant Physiol. 2016, 196, 93-98. [CrossRef]

20. Ayerza, R.; Coates, W. Ground chia seed and chia oil effects on plasma lipids and fatty acids in the rat. Nutr. J. 2005, 25, 995-1003. [CrossRef]

21. Bushway, A.A.; Belyea, P.R.; Bushway, R.J. Chia seed as a source of oil, polysaccharide, and protein. J. Food Sci. 1981, 46, 1349-1350. [CrossRef]

22. Capitani, M.I.; Spotorno, V.; Nolasco, S.M.; Tomás, M.C. Physicochemical and functional characterization of by-products from chia (Salvia hispanica L.) seeds of Argentina. LWT Food Sci. Technol. 2012, 45, 94-102. [CrossRef]

23. da Silva Marineli, R.; Moraes, E.A.; Lenquiste, S.A.; Godoy, A.T.; Eberlin, M.N.; Maróstica, M.R., Jr. Chemical characterization and antioxidant potential of Chilean chia seeds and oil (Salvia hispanica L.). LWT Food Sci. Technol. 2014, 59, 1304-1310. [CrossRef]

24. da Silva Marineli, R.; Moura, C.S.; Moraes, E.A.; Lenquiste, S.A.; Lollo, P.C.B.; Morato, P.N.; Maróstica, M.R., Jr. Chia (Salvia hispanica L.) enhances HSP, PGC-1 $\alpha$ expressions and improves glucose tolerance in diet-induced obese rats. Nutr. J. 2015, 31, 740-748. [CrossRef] [PubMed]

25. Poudyal, H.; Panchal, S.K.; Waanders, J.; Ward, L.; Brown, L. Lipid redistribution by $\alpha$-linolenic acid-rich chia seed inhibits stearoyl-CoA desaturase-1 and induces cardiac and hepatic protection in diet-induced obese rats. J. Nutr. Biochem. 2012, 23, 153-162. [CrossRef]

26. Porras-Loaiza, P.; Jiménez-Munguía, M.T.; Sosa-Morales, M.E.; Palou, E.; López-Malo, A. Physical properties, chemical characterization and fatty acid composition of Mexican chia (Salvia hispanica L.) seeds. Int. J. Food Sci. Technol. 2014, 49, 571-577. [CrossRef]

27. Ng, P.L.L.; Ferrarese, M.L.L.; Huber, D.A.; Ravagnani, A.L.S.; Ferrarese-Filho, O. Canola (Brassica napus L.) seed germination influenced by cinnamic and benzoic acids and derivatives: Effects on peroxidase. Seed Sci. Technol. 2003, 31, 39-46. [CrossRef] 
28. Gerig, T.M.; Blum, U. Effects of mixtures of 4 phenolic acids on leaf-area expansion of cucumber seedlings grown in Portsmouth B1 soil materials. J. Chem. Ecol. 1991, 17, 29-40. [CrossRef]

29. Yan, F.; Liu, Y.; Sheng, H.; Wang, Y.; Kang, H.; Zeng, J. Salicylic acid and nitric oxide increase photosynthesis and antioxidant defense in wheat under UV-B stress. Biol. Plant. 2016, 60, 686-694. [CrossRef]

30. Einhellig, F.A.; Rasmussen, J.A. Effects of three phenolic acids on chlorophyll content and growth of soybean and grain sorghum seedlings. J. Chem. Ecol. 1979, 5, 815-823. [CrossRef]

31. Merzlyak, M.N.; Kovrizhnikh, V.A.; Timofeev, K.N. Superoxide mediated chlorophyll allomerization in a dimethyl sulphoxide-water mixture. Free Radic. Res. Commun. 1991, 15, 197-201. [CrossRef]

32. Klein, A.; Keyster, M.; Ludidi, N. Caffeic acid decreases salinity-induced root nodule superoxide radical accumulation and limits salinity-induced biomass reduction in soybean. Acta Physiol. Plant. 2013, 35, 3059-3066. [CrossRef]

33. Smirnoff, N. The role of active oxygen in the response of plants to water deficit and desiccation. New Phytol. 1993, 125, 27-58. [CrossRef]

34. Sheokand, S.; Bhankar, V.; Sawhney, V. Ameliorative effect of exogenous nitric oxide on oxidative metabolism in $\mathrm{NaCl}$ treated chickpea plants. Braz. J. Plant Physiol. 2009, 22, 81-90. [CrossRef]

35. Flowers, T.J.; Yeo, A.R. Ion relations of plants under drought and salinity. Aust. J. Plant Physiol. 1986, 13, 75-91. [CrossRef]

36. Hasegawa, P.M.; Bressan, R.A.; Zhu, J.K.; Bohnert, H.J. Plant cellular and molecular responses to high salinity. Annu. Rev. Plant Physiol. Plant Mol. Biol. 2000, 51, 463-499. [CrossRef]

37. García-Mata, C.; Lamattina, L. Nitric oxide induces stomatal closure and enhances the adaptive plant responses against drought stress. Plant Physiol. 2001, 126, 1196-1204. [CrossRef]

38. Hossain, M.A.; Hoque, M.A.; Burritt, D.J.; Fujita, M. Proline protects plants against abiotic oxidative stress: Biochemical and molecular mechanisms. In Oxidative Damage to Plants; Academic Press: Cambridge, MA, USA, 2014; pp. 477-522.

39. Yancey, P.H. Organic osmolytes as compatible, metabolic and counteracting cytoprotectants in high osmolarity and other stresses. J. Exp. Biol. 2005, 208, 2819-2830. [CrossRef]

40. Sanchez, D.H.; Schwabe, F.; Erban, A.; Udvardi, M.K.; Kopka, J. Comparative metabolomics of drought acclimation in model and forage legumes. Plant Cell Environ. 2012, 35, 136-149. [CrossRef]

41. Matysik, J.; Alia, B.B.; Mohanty, P. Molecular mechanisms of quenching of reactive oxygen species by proline under stress in plants. Curr. Sci. 2002, 82, 525-532.

42. Mathew, S.; Abraham, T.E.; Zakaria, Z.A. Reactivity of phenolic compounds towards free radicals under in vitro conditions. J. Food Sci. Technol. 2015, 52, 5790-5798. [CrossRef]

43. Hiscox, J.D.; Israelstam, G.F. A method for the extraction of chlorophyll from leaf tissue without maceration. Can. J. Bot. 1979, 57, 1332-1334. [CrossRef]

44. Velikova, V.; Yordanov, I.; Edreva, A. Oxidative stress and some antioxidant systems in acid rain treated bean plants: Protective role of exogenous polyamines. Plant Sci. 2000, 151, 59-66. [CrossRef]

45. Egbichi, I.; Keyster, M.; Jacobs, A.; Klein, A.; Ludidi, N. Modulation of antioxidant enzyme activities and metabolites ratios by nitric oxide in short-term salt stressed soybean root nodules. S. Afr. J. Bot. 2013, 88, 326-333. [CrossRef]

46. Stewart, R.R.; Bewley, J.D. Lipid peroxidation associated with accelerated aging of soybean axes. Plant Physiol. 1980, 65, 245-248. [CrossRef] [PubMed]

47. Bates, L.S.; Waldren, R.P.; Teare, I.D. Rapid determination of free proline for water-stress studies. Plant Soil 1973, 39, 205-207. [CrossRef]

48. Nxele, X.; Klein, A.; Ndimba, B.K. Drought and salinity stress alters ROS accumulation, water retention, and osmolyte content in sorghum plants. S. Afr. J. Bot. 2017, 108, 261-266. [CrossRef]

49. Sairam, R.K.; Srivastava, G.C.; Saxena, D.C. Increased antioxidant activity under elevated temperatures: A mechanism of heat stress tolerance in wheat genotypes. Biol. Plant. 2000, 43, 245-251. [CrossRef]

50. Ullah, S.; Kolo, Z.; Egbichi, I.; Keyster, M.; Ludidi, N. Nitric oxide influences glycine betaine content and ascorbate peroxidase activity in maize. S. Afr. J. Bot. 2016, 105, 218-225. [CrossRef]

51. IKiliç, I.; Yeşiloğlu, I.Y. Spectroscopic studies on the antioxidant activity of $p$-coumaric acid. Spectrochim. Acta Part A Mol. Biomol. Spectrosc. 2013, 115, 719-724. 
52. Shen, Y.; Song, X.; Li, L.; Sun, J.; Jaiswal, Y.; Huang, J.; Liu, C.; Yang, W.; Williams, L.; Zhang, H.; et al. Protective effects of $p$-coumaric acid against oxidant and hyperlipidemia-an in vitro and in vivo evaluation. Biomed. Pharmacother. 2019, 111, 579-587. [CrossRef]

53. Rajendrakumar, C.S.; Suryanarayana, T.; Reddy, A.R. DNA helix destabilization by proline and betaine: Possible role in the salinity tolerance process. FEBS Lett. 1997, 410, 201-205. [CrossRef]

(C) 2019 by the authors. Licensee MDPI, Basel, Switzerland. This article is an open access article distributed under the terms and conditions of the Creative Commons Attribution (CC BY) license (http://creativecommons.org/licenses/by/4.0/). 